\title{
A comparison of five methods to assess embolism resistance in trees
}

\author{
A.S. Sergent ${ }^{\mathrm{a}, \mathrm{b}, *}$, S.A. Varela ${ }^{\mathrm{a}}$, T.S. Barigah ${ }^{\mathrm{c}}, \mathrm{E}$ Badel $^{\mathrm{c}}$, H. Cochard $^{\mathrm{c}}$, G. Dalla-Salda ${ }^{\mathrm{a}}$, S. Delzon ${ }^{\mathrm{d}}$, \\ M.E. Fernández ${ }^{\mathrm{b}, \mathrm{e}}$, J. Guillemot ${ }^{\mathrm{f}, \mathrm{g}}$, J. Gyenge ${ }^{\mathrm{b}, \mathrm{e}}$, L.J. Lamarque ${ }^{\mathrm{d}, \mathrm{h}}$, A. Martinez-Meier ${ }^{\mathrm{a}}$, \\ P. Rozenberg ${ }^{\mathrm{i}}$, J.M. Torres-Ruiz ${ }^{\mathrm{c}}$, N.K. Martin-StPaul ${ }^{\mathrm{j}}$

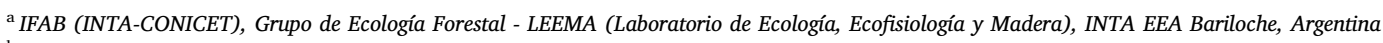 \\ ${ }^{\mathrm{b}}$ Consejo Nacional de Investigaciones Científicas y Técnicas (CONICET), Argentina \\ ${ }^{\mathrm{c}}$ Université Clermont Auvergne, INRAE, PIAF, 63000 Clermont-Ferrand, France \\ ${ }^{\mathrm{d}}$ Université Bordeaux, INRAE, BIOGECO, 33615 Pessac, France

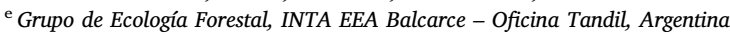 \\ ${ }^{\mathrm{f}}$ Univ Montpellier, CIRAD, INRA, IRD, Montpellier SupAgro, Eco\&Sols, 34060 Montpellier, France \\ ${ }^{\mathrm{g}}$ Universidade de São Paulo-ESALQ, 13418-900 Piracicaba, SP, Brazil \\ ${ }^{\mathrm{h}}$ Département des Sciences de l'Environnement, UQTR, Trois-Rivières, Québec, Canada \\ ${ }^{\mathrm{i}}$ INRAE, ONF, UMR 0588 BioForA, 45000 Orléans, France \\ ${ }^{\mathrm{j}}$ INRAE, URFM, 84000 Avignon, France
}

\section{A R T I C L E I N F O}

\section{Keywords:}

Xylem embolism

Methods comparison

Drought tolerance traits

Vulnerability curve

\begin{abstract}
A B S T R A C T
Vulnerability to drought-induced embolism is a key trait that shapes drought resistance and that could be increasingly used to design climate-smart forest management guidelines and to anticipate the outcome of climate change on populations dynamics and ecosystems functioning. A panel of methods is currently available to measure embolism resistance. This makes crucial a proper identification of which methods are the most accurate for determining this trait. However, the measurement of embolism resistance is sensitive to numerous artifacts that may lead to large errors for a given species. In addition, not all methods are easily accessible because of the cost of some large equipment and/or certain lab facilities. The emergence of the easy and low cost Pneumatic method allows to perform vulnerability curves at high throughput. However, only few studies have evaluated the reliability of this method compared to others. In this study, we proposed a comparison of five methods that allowed to assess embolism resistance in eleven tree species with contrasting xylem anatomy and vessels length (six short vessel angiosperms, two tracheid bearing conifers and three long-vessel angiosperms), covering a large part of the range of embolism resistance observed in trees. Consistent results were obtained among all the methods for short-vessel angiosperm species. In tracheid-bearing conifers, the Pneumatic method overestimated vulnerability to embolism. In long-vessel species, the Pneumatic method led to inconsistent results with accurate vulnerability to cavitation curves (VCs) for one species but led to r-shaped VCs with a underestimation of incipient embolism for the two other ones. The comparison of VC parameters with turgor loss point is proposed as an indicator of the validity of the VCs. The conditions of validity, the advantages and pitfalls of the five methods are discussed. Our results warned against the widespread usages of some methods before rigorous validation tests have been performed.
\end{abstract}

\section{Introduction}

Plant resistance to drought depends on the ability of the plant vascular system to maintain water transport during water stress. This can be achieved through both a timely regulation of leaf transpiration through stomatal closure and the ability of the vascular system to keep xylem conduits water-filled, and therefore conductive, under high tensions encountered during soil drought coupled with high evaporative demand (Cochard et al., 1996; Martin-StPaul et al., 2017; Salleo et al., 2000; Sperry and Pockman, 1993). This latter property is called xylem embolism resistance. Embolism results from cavitation, that is the change in the state of water from liquid to gas, and the subsequent disruption of sap transport in xylem conduits that occurs during drought (Tyree and Dixon, 1986; Tyree and Sperry, 1989; Zimmermann, 1983). Given that species operate in a reduced range in terms of stomatal regulation (Martin-StPaul et al., 2017), embolism

\footnotetext{
* Corresponding author at: Modesta Victoria 4450, CP 8400, San Carlos de Bariloche, Río Negro, Argentina.

E-mail address: sergent.annesophie@inta.gob.ar (A.S. Sergent).
} 
resistance represents a pivotal trait to discriminate species ability to tolerate drought (Larter et al., 2017; Lens et al., 2016). As a matter of fact, at the interspecific level, resistance to embolism is considered to be a driver of vegetation distribution along aridity gradients (Choat et al., 2012; Cochard et al., 2008; Delzon et al., 2010; Maherali et al., 2004; Pockman and Sperry, 2000).

Embolism resistance is typically evaluated by constructing vulnerability curves (VCs), defined by the relationship between xylem water potentials and corresponding degrees of xylem embolism. Two important parameters can be retrieved from these VCs to characterize the species' embolism resistance: the water potential inducing 50\% loss of conductivity $\left(\Psi_{50}, \mathrm{MPa}\right)$ and the rate of percent loss of conductivity (PLC) increase per water potential drop (Slope, \%. $\mathrm{MPa}^{-1}$ ). Over the past four decades, different methods have been developed to construct VCs, differing in the way plant samples are dehydrated and the amount of embolism is assessed (Cochard et al., 2013).

Among the oldest methods, the Bench-dehydration method has long been considered as a reference because branches or intact plants are dehydrated progressively on a bench, simulating the natural process of dehydration that would occur during a drought in the field (Bréda et al., 1993; Cochard et al., 1996, 2013). Water potential is regularly monitored with a pressure chamber or a psychrometer during dehydration and PLC is measured in short sub-samples by measuring water-flow before and after flushing the embolism. PLC is generally measured gravimetrically or using a flow meter under positive pressure. Important disadvantage remains, however, as this method is highly destructive (it requires one branch for each measurement point) and measurements are time-consuming. Additionally, this method can be prone to artifacts. Xylem conductivity (at the proximal end) can be blocked by air bubbles or impurities injected in the perfusion solution (Sperry and Saliendra, 1994). In angiosperm and more specifically in long vessels species, an artificial embolism can occur if great care is not taken to relax xylem tension during the sampling (Wheeler et al., 2013) and/or the cutting procedure (Torres-Ruiz et al., 2015). Nevertheless, if applied carefully, the Bench-dehydration method has proven to be highly accurate (Choat et al., 2010; Cochard et al., 2010, 2013; TorresRuiz et al., 2015).

Another option to the direct gravimetrical estimation of conductivity loss, is to measure the level of embolism, quantifying the amount of embolized conduits, by direct visualization after scanning samples with X-Ray micro-computed-tomography (Micro-CT) (Brodersen et al., 2010; Choat et al., 2015; Torres-Ruiz et al., 2015). Synchrotron-based micro-CT provides the possibility of measuring embolism on intact plants offering a reliable reference (Cochard et al., 2015). Nevertheless, X-rays can impact the hydraulic functioning of the plant, after several scans since $\mathrm{x}$-rays can potentially damage living cells and vessels that are directly in the x-ray beam but not affect water conduits that are dead cells. Moreover, accurate estimation of hydraulic conductivity implies to differentiate functional conducts (i.e. conductive water-filled) from non-functional fluid-filled conducts. Two alternatives exist to avoid this potential artifact, the use of a contrast agent (Pratt and Jacobsen, 2018) or to do a final cut in the air. Additionally, this method is still very time-consuming and getting access to synchrotron facilities or lab-based Micro-CT equipment is complicated and expensive.

Drawing on the Bench-dehydration principle, the Pneumatic method was recently proposed as a new method for evaluating resistance to embolism. It is based on the estimation of the volume of air discharged from a sample during a dehydration sequence (Pereira et al., 2016). The basic idea is that air discharge increases with embolism rate, as water in previously functional conduits is replaced by air when embolism occurs. As air discharge and water potential are monitored concurrently and repeatedly on the same branch-sample, the Pneumatic method allows getting one VC per sample, which renders the method less destructive than the classical Bench-dehydration and to characterize embolism resistance at the individual level. Additionally, because air discharge measurements take only a few minutes and measurements can be automated, this method allows measuring several samples at the same time (Pereira et al., 2016, 2019), resolving the time-consuming issue of the Bench-dehydration method. Nevertheless, recent studies indicated that this method could largely underestimate embolism resistance on tracheid's species and some significant differences can be observed in some angiosperm species when compared with flow-centrifuge method (Pereira et al., 2016; Zhang et al., 2018), but there are still few validations of this method.

Other methods were designed and have been used to construct VCs at relatively high throughput since the 90s. One of them, the Air-injection method, consists in inducing embolism progressively by forcing pressurized air to enter the xylem conduits of the sample through a tied pressure collar (sleeve) (Cochard et al., 1992; Salleo et al., 1992). After each step of air injection, PLC can be determined gravimetrically as in the Bench-dehydration method. The system can be automatized to facilitate measurements, and some prototypes recently developed, now allow building a VC in less than one hour (Dalla-Salda, pers. comm.). There are some reported artifacts. For instance, this method may require notching the sample in the absence of cut petioles or cut sidebranches, in order to allow air to reach the xylem (Sperry and Saliendra, 1994). Additionally, in long-vessel angiosperms, artifacts were reported because samples included open vessels (Choat et al., 2010; Torres-Ruiz et al., 2014). Such artifacts generally produce highly vulnerable curves, the so-called $r$-shaped curves (Cochard et al., 2010). These artifacts can be avoided by using samples longer than the maximal vessels length, placing the pressure-collar in a central portion of the sample and using an adapted pressure-collar length (Ennajeh et al., 2011a; Martin-StPaul et al., 2014). Another type of method relies on the centrifugal force, in which, stem or branch samples are spun at increasing speed to mimic the tension experienced by xylem water columns during drought (Flow-centrifuge; Alder et al., 1997). The loss of conductivity is determined gravimetrically after each spin (Alder et al., 1997; Torres-Ruiz et al., 2017). In the more recently developed Flowcentrifuge device, conductivity is measured while the sample is spinning, which considerably accelerates the measurement procedure (Cochard, 2002; Cochard et al., 2005). As the Air-injection method, the Flow-centrifuge method is also prone to open-vessel artifacts in angiosperm species (Choat et al., 2010; Martin-StPaul et al., 2014; TorresRuiz et al., 2014). To avoid underestimation of embolism resistance the rotor should be longer than the maximal vessel length. Alternatively, simple tests can be applied to assess the level of artifactual embolism at low xylem tension (Torres-Ruiz et al., 2017), and corrective models can eventually be applied (López et al., 2019). There are other methods to assess the level of embolism including the old acoustic methods (Milburn and Johnson, 1966) and the recent optical method (Brodribb et al., 2017), but they are not treated in this study.

The two relative high-throughput methods, Air-injection and Flowcentrifuge, are currently increasingly used to characterize intra-specific variability of embolism resistance since this variation is becoming a key issue to study the adaptability of tree population to future climate (Chauvin et al., 2019; Lamy et al., 2013; López et al., 2016; Torres-Ruiz et al., 2019; Wortemann et al., 2011). However, this requires to quantify and highlight intraspecific differences when they exist but also to ensure that measurements done with different methods are comparable at the species level. Few studies have assessed if both methods are fully comparable at the intraspecific level, performing the comparison on the same individuals.

As explained above, the last decades have known an intense debate regarding the ability of all these methods to produce accurate VCs and different artifacts were observed in all of them. Artifacts reported depends on both the methodology and the species wood properties, mostly related to the maximum vessel length (Cochard et al., 2013; Torres-Ruiz et al., 2014). To clarify the condition of the method applicable for a range of species it thus appears crucial to compare VC parameters obtained with various methods over a range of species. 
It is also important to provide independent traits for validation that would help decipher if a VC is reliable or not. In the sequence of drought response mechanisms, stomatal closure before embolism formation has been theoretically advanced as a fundamental component (Jones and Sutherland, 1991; Sperry et al., 2002). In experimental studies, leaf turgor loss has been shown to occur before or close to any significant level of xylem embolism in branches (Li et al., 2018; MartinStPaul et al., 2017) and in leaves (Creek et al., 2019; Skelton et al., 2018). On this basis, it has been proposed that parameters derived from the Pressure-Volume curves, such as the leaf turgor loss point $\left(\pi_{\mathrm{tlp}}\right)$, could be compared to the thresholds water potential of incipient for embolism $\left(\Psi_{12}\right)$ in branches in order to have a good indication of the reliability of a VC (Cochard et al., 2019; Martin-StPaul et al., 2014).

In this study, our main aim was to provide a general comparison among the different methods used for determining plant embolism resistance described earlier, across species with different wood anatomy (interspecific analysis) and within one of them (intraspecific analysis). Additionally, we also performed Pressure-Volume curves to evaluate if $\pi_{\text {tlp }}$ can be used to contribute assessing the validity of the VC by verifying that turgor loss is reached before or close to incipient embolism formation.

\section{Materials and methods}

\subsection{Plant material and experimental design}

The study was focused on eleven tree species. Preliminary to xylem embolism vulnerability measurements, maximal vessel length was measured for each species (Table1) using the air-infiltration technique (Ewers and Fisher, 1989; Zimmermann and Jeje, 1981). The eleven species included six short-vessel angiosperms (maximum vessel length $<=0.25 \mathrm{~m}$ ), three long-vessel angiosperms $(>=0.90 \mathrm{~m})$ and two tracheid-bearing gymnosperms species (Table 1). Among them, seven were native of Patagonian forests (South-America) for which only a few VCs data are yet available without any information about their vessel lengths. Among Patagonian species, the six short-vessel angiosperm species were Nothofagus antarctica (G. Forst.) Oerst., Nothofagus pumilio (Poepp. \& Endl.) Krasser, Lomatia hirsuta (Lam.) Diels ex J.F. Macbr., Maytenus boaria Molina, Schinus patagonicus (Phil.) I.M. Johnst. ex Cabrera and Embothrium coccineum J.R. Forst. \& G. Forst., and the tracheid-bearing species was Austrocedrus chilensis (D. Don) Pic.Serm. \& Bizzarri. Those species are widespread in Patagonian forests subjected to different precipitation levels and thus are expected to exhibit different degrees of drought resistance (Supplementary 1, Table S1). Branch samples of those species were collected in adult trees (except for $N$. pumilio for which 2-year-old seedlings were used) in the same region of Río Negro Province, Argentina, within a radius of $50 \mathrm{~km}$ around San Carlos de Bariloche city ( $\left.41^{\circ} 08^{\prime} 03^{\prime} \mathrm{S} ; 71^{\circ} 18^{\prime} 30^{\prime} \mathrm{W}\right)$. Additionally, to enlarge our dataset with distinct xylem anatomy and vessel lengths, four other species native of the northern hemisphere were included, one conifer (Cedrus deodara (Roxb.) G.Don) and three long-vessel angiosperm species (Quercus ilex L., Laurus nobilis L. and Olea europaea L.). Branches of $C$. deodara were collected from adult specimens of forestgrown trees on the Cézeaux Campus of Clermont-Auvergne University, Clermont-Ferrand, France $\left(45^{\circ} 45^{\prime} 46^{\prime \prime} \mathrm{N}, 3^{\circ} 06^{\prime} 51^{\prime \prime} \mathrm{E}\right)$ and from adult trees growing in Bariloche, Argentine $\left(41^{\circ} 08^{\prime} 03^{\prime} \mathrm{S} ; 71^{\circ} 18^{\prime} 30^{\prime} \mathrm{W}\right)$. For the three long vessel species (Q. ilex, L. nobilis and O. europaea) data were collected on seedlings of one to three-years-old and on adult trees. For more details about the harvest moments and the type of sample used for each method see Supplementary Material 2.

For the six short-vessel angiosperm species, four methods were compared (Bench-dehydration, Pneumatic, Air-injection and Flowcentrifuge). For the three long-vessel species, the comparison was focused on Micro-CT, Pneumatic and Flow-centrifuge methods since the use of Air-injection on long-vessel species has been tested previously (Choat et al., 2010; Ennajeh et al., 2011b; Martin-StPaul et al., 2014).

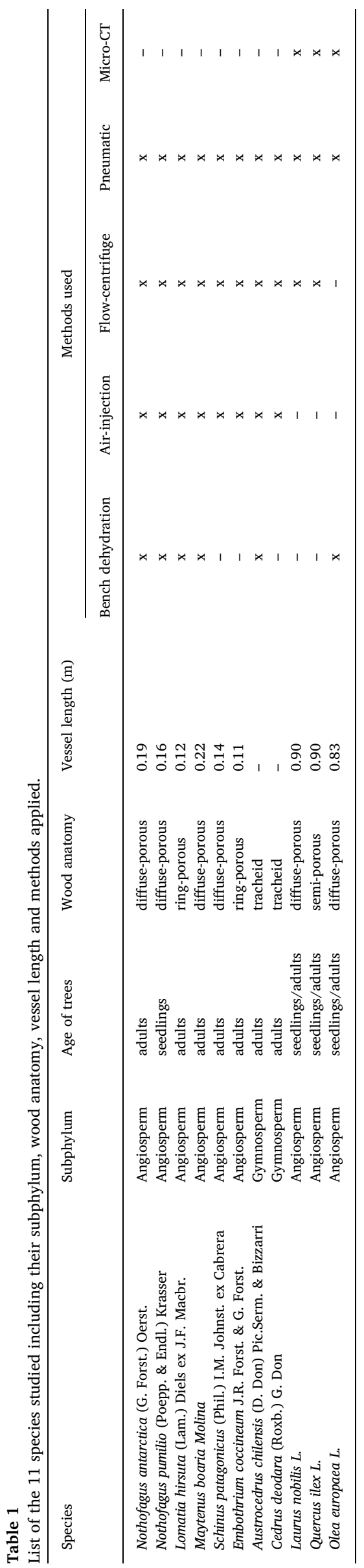


For the two conifers, the comparison was focused on the Air-injection, the Pneumatic and the Flow-centrifuge methods. In addition, VC parameters obtained with Air-injection and Flow-centrifuge methods from individuals of three distinct populations of $A$. chilensis growing in three different provenance regions (Pastorino et al., 2015) were compared, to test if both methods are capable of characterizing the intraspecific variability in this conifer species (more information about provenances and sampling in Supplementary Material 2). All measurements were obtained for this study, except for Micro-CT and Flow centrifuge methods in L. nobilis (Lamarque et al., 2018) and Micro-CT and bench-dehydration in O. europaea (Torres-Ruiz et al., 2014, 2017).

\subsection{Methods to assess embolism resistance}

\subsubsection{Bench-dehydration method}

For the short-vessel angiosperm species, Bench-dehydration VCs were obtained following the method described by Sperry (1986). In the lab, branches were progressively dehydrated on a bench under room conditions during different time intervals from one hour to few days to reach the range of water potentials required to construct VCs. Before water-potential measurements with a pressure-chamber (PMS Instrument Company, Albany, OR, USA), three to five leaves were covered for at least one hour to allow the equilibrium between the leaf and xylem water potential. The average of the measurements of at least two leaves was regarded as the mean xylem water-potential. Once the target pressure was achieved, the branch was sampled to assess its loss of hydraulic conductivity (PLC). For angiosperm species to eliminate potential cutting artifact (Torres-Ruiz et al., 2015), branches were rehydrated in water and shortening progressively underwater to release the xylem tension before sampling the xylem segment of interest (i.e. the 3$\mathrm{cm}$ long segment in which PLC is measured). Terminal branch segment (grown in the current year) were used to assess the PLC. For all the species, the distal end of the branch-segment was connected to a $1 \mathrm{~m}$ high water column filled with a solution of demineralized and filtered water that contained $1 \mathrm{mM} \mathrm{CaCl}$ and $10 \mathrm{mM} \mathrm{KCl}$. The proximal end was inserted to a tubing system connected to a reservoir lying on a precision balance to gravimetrically determine the flow rate through the branch segment. Three repetitions of measurements of continuous mass variation within 2 min intervals were used to determine the mean flow rate through the branch-segment $\left(\mathrm{F}, \mathrm{kg} . \mathrm{s}^{-1}\right)$. The initial hydraulic conductivity of the stem-segment $\left(\mathrm{k}_{\mathrm{h}}, \mathrm{kg} \cdot \mathrm{m} \cdot \mathrm{s}^{-1} \cdot \mathrm{MPa}^{-1}\right)$ was calculated as the ratio between the flow rate through the segment and the pressure head $(10 \mathrm{kPa})$, normalized by the length of the segment. For angiosperm species, to calculate maximal hydraulic conductivity $\left(\mathrm{k}_{\mathrm{hmax}}\right.$, kg.m.s ${ }^{-1} \cdot \mathrm{MPa}^{-1}$ ), segments were then flushed with the same solution at $150 \mathrm{kPa}$ at least for $5 \mathrm{~min}$ or until no more bubbles came out of the sample to remove emboli. The flushed segments were connected again to the balance system to measure their maximum flow rate under the pressure gradient of $10 \mathrm{kPa}$. For A. chilensis, a gymnosperm species, successive segments of the same branch were used to assess the PLC during the dehydration of the branch. The $\mathrm{k}_{\mathrm{h}}$ before dehydration was considered as $\mathrm{k}_{\mathrm{hmax}}$ for PLC calculations since embolism removal by flushing is not possible due to the sealing of the torus against the pit wall when flushing. For all species, the PLC was calculated as:

PLC $=100 *\left(1-\mathrm{k}_{\mathrm{h}} / \mathrm{k}_{\mathrm{hmax}}\right)(1)$

where $k_{h}$ is the measured conductivity for each water potential and $\mathrm{k}_{\mathrm{hmax}}$ is the maximal conductivity of the same branch-segment.

The VCs were plotted as the relationship between the xylem water potential and the loss of hydraulic conductivity (PLC).

\subsubsection{Micro-CT method}

For long-vessel species (Q. ilex, L. nobilis and O. europaea), micro computed tomography (Micro-CT) was used to measure embolism progression at different levels of water potential on intact plants seedlings. For $L$. nobilis, direct visualization of embolized xylem vessels in the main stems of intact seedlings was carried out during two campaigns (see Lamarque et al., 2018 for the detailed protocol). Briefly, a total of 14 well-watered plants from one- to three-year-old were depoted to reach different water potential during 5 days campaigns. Tomographic observations were conducted during the first campaign at UGCT (Ghent

University, Belgium) using the HECTOR scanner equipped with polychromatic a $240-\mathrm{kV}$ X-ray tube (X-ray WorX, Garbsen, Germany) and a 1620 flat-panel detector (PerkinElmer, Waltham, MA, USA), and during the second campaign at SOLEIL (Paris, France) using the PSICHÉ high flux (3.1011 photons $\mathrm{mm}^{-1}$ ) 25-keV monochromatic X-ray beam (King et al., 2016). Each seedling was scanned three times during dehydration focusing on the same location along the stem. Each scan yielded a $2000 \times 2000 \times 2000$ voxels volume. The tomographic reconstructions were carried out at UGCT and at SOLEIL, respectively (Dierick et al., 2004, Paganin et al., 2002, Mirone et al., 2014). The corresponding level of plant dehydration was monitored through water potential measurements conducted with the Schölander pressure chamber using a single leaf located below the scanned area to avoid an underestimation of the water potential at the scan location (Charrier et al., 2016).

For $Q$. ilex and $O$. europaea, direct visualizations of embolized xylem vessels in the main stems along with leaf water potential were performed with the PSYCHE beamline at SOLEIL Synchrotron during the 2015 campaign using the same protocols as for $L$. nobilis. Seven to nine 2 to 3 -years-old seedlings were used for $Q$. ilex and O. europaea respectively.

In both species, the same settings were used as during the second campaign developed for $L$. nobilis. Two weeks before the experiment, we progressively stop watering the plants to reach a large range of xylem water potential among the study individuals at the onset of the campaigns. Some seedlings were depoted at the synchrotron to accelerate the dehydration. During each campaign, different seedlings were scanned along the stem to cover a range of water potential between -1 and $-9 \mathrm{MPa}$. Seedlings were scanned between one and three times over the campaigns. Plant water potential was concurrently measured with a Schölander pressure chamber.

In all cases, embolism observations were conducted for each scan from a transverse cross-section taken from the center of the scan volume. The $\mathrm{k}_{\mathrm{h}}$ was determined by computing the individual area and diameter of both air- and water-filled vessels. Vessel visualization, i.e., the distinction between functional vessels from non-functional xylem conduits and fibers, and vessel diameter calculations were facilitated by using a final scan ("final cut") that was generated for each stem section. Final cuts represented scans performed after samples were cut in the air ca. $2 \mathrm{~mm}$ above the corresponding scanned stem volume and where functional vessels with sap under tension immediately filled with air. The $k_{h}$ of air-filled vessels of each cross-section was calculated according to the Hagen-Poiseuille equation:

$$
\mathrm{k}_{\mathrm{h}}=\Sigma \pi \mathrm{D}^{4} / 128 \eta(2)
$$

where $\mathrm{D}$ is the diameter of vessels (m) and $\eta$ is the water viscosity (1.002 $\mathrm{MPa} \mathrm{s}^{-1}$ at $20^{\circ} \mathrm{C}$ ). The $\mathrm{k}_{\max }$ was determined as the theoretical hydraulic conductivity of all functional vessels as based on a crosssection after the final cut. The theoretical loss of hydraulic conductivity (PLC, \%) was then determined as in Equation 1.

\subsubsection{Flow-centrifuge method}

Measurements were carried out in a "Cavitron" device (Cochard, 2002; Cochard et al., 2005), at the high-throughput phenotyping platforms for hydraulic traits ("Caviplace", University of Bordeaux, Talence, France, and "Cavihome”, INRAE, Clermont-Ferrand, France). To avoid the open-vessels artifact, VCs were performed using three different rotor sizes $(0.28,0.42$ and $1 \mathrm{~m})$ depending on the maximal vessel length. Thus, samples were installed in rotors showing a longer diameter than the maximum vessel length for each species. For some species, two sizes of the rotor were tested to ensure the reliability of the VCs (Supplementary Material 3, fig S1). In the lab, all branches were 
cut to obtain $0.28 \mathrm{~m}$ (tracheids species), $0.42 \mathrm{~m}$ (short-vessel species), and $1 \mathrm{~m}$ (long-vessel species) long samples. Each sample end was debarked and inserted into a transparent reservoir containing a solution of filtered and demineralized water with $1 \mathrm{mM} \mathrm{CaCl}_{2}$ and $10 \mathrm{mM} \mathrm{KCl}$. The difference in solution levels between the two reservoirs creates a hydrostatic gradient that generates water flow rates through the study sample and allows to measure $\mathrm{k}_{\mathrm{h}}$ (see Cochard et al., 2005 for further details). Xylem pressure was first set to a reference pressure $(-0.1 \mathrm{MPa})$ for measuring the $\mathrm{k}_{\mathrm{hmax}}$. The centrifugation speed was then set to a higher value for $3 \mathrm{~min}$ to expose the sample to more negative pressure. The hydraulic conductivity was measured three times for each pressure level and the average was used to compute the mean PLC at that pressure. The procedure was repeated for at least eight pressure levels until the loss of conductivity reached at least $80 \%$. Rotor velocity was monitored with a 10 r.p.m. resolution electronic tachymeter (A2108-LSR232; Compact Instruments, Bolton, UK). The Cavisoft software (version 2.0; BIOGECO, University of Bordeaux, Talence, France) was used for hydraulic conductivity and PLC estimation.

\subsubsection{Air-injection method}

For the short vessel species, embolism resistance measurements were carried out using the Air-injection method with an automated device called "Embolitron" (Dalla-Salda, unpublished data). The principle of the technique is to induced embolism by injecting air or nitrogen into a sleeve around the sample at different pressures and then measuring the variation in its hydraulic conductivity. Recommendations of Ennajeh et al., (2011a) were considered in order to avoid known artifacts. In the lab, all branches were debarked and cut to obtain $0.15 \mathrm{~m}$ (tracheid bearing species) and $0.3 \mathrm{~m}$ to $0.40 \mathrm{~m}$ (short vessel angiosperm species) long samples, to obtain samples twice long as the maximum vessel length. The samples were then inserted into a sleeve, with the two ends protruding out of the sleeve whereas particular attention was paid to correctly place the chamber (Supplementary Material 3). The branch segment was connected to a $0.85 \mathrm{~m}$ high column filled with a solution of filtered and demineralized water that contained $1 \mathrm{mM} \mathrm{CaCl}_{2}$ and $10 \mathrm{mM} \mathrm{KCl}$., inducing a pressure gradient of $8.5 \mathrm{kPa}$. Embolism was induced injecting compressed nitrogen in the sleeve for $2 \mathrm{~min}$. A total of 9 steps of pressure from 0 to $8 \mathrm{MPa}$ (increment of $1 \mathrm{MPa}$ ) or from 0 to $4 \mathrm{MPa}$ (increment of $0.5 \mathrm{MPa}$ ) were applied using a pressure regulator (AirCom ${ }^{\circledR}$ Pneumatic GmbH, Ratingen, Deutschland). Hydraulic conductivity was gravimetrically measured with a precision scale (KERN \& SOHN GmbH, Ziegelei, Balingen, Deutschland). We waited for at least $5 \mathrm{~min}$ after each pressurization allowing the system to equilibrate. The $\mathrm{k}_{\mathrm{h}}$ was calculated with the same methodology as for the Bench-dehydration method. The highest $k_{h}$ value, usually obtained before the first air injection or after air injection at $1 \mathrm{MPa}$ was used as $\mathrm{k}_{\mathrm{hmax}}$. PLC was calculated as the ratio between $k_{h}$ and $k_{\max }$. PLC values versus applied pressure values were plotted to obtain the VCs.

\subsubsection{Pneumatic method}

The Pneumatic method was conducted according to Pereira et al. (2016). Thus, $0.50 \mathrm{~m}$ to $2.00 \mathrm{~m}$-long branches (two times higher or equal to the species maximum vessel length) were used. In the lab, the basal end of each branch was connected to the Pneumatic apparatus via a three-way stopcock, which included a syringe to generate a vacuum in the system and a pressure sensor (Omega Engineering, Norwalk, USA). Once the branch end was connected to the pneumatic tubing system, the tubing was not replaced and the branch ends were not shaved before a measurement was taken. The rigid plastic tube between the branch end and the pressure sensor acted as a vacuum reservoir. Firstly, the branch-vacuum reservoir pathway was closed, i.e., the branch end was open to the atmosphere. A negative pressure of ca. $40 \mathrm{kPa}$ was applied to the vacuum reservoir by pulling the syringe plunger. Secondly, the vacuum reservoir-syringe pathway was closed and the pathway between the branch and the vacuum reservoir was opened.
The initial pressure was measured immediately after connecting the branch end to the vacuum reservoir. After extracting the air from the branch to the vacuum reservoir for $2 \mathrm{~min}$, the final pressure was measured. Additionally, a leak test was run before each air-discharge measurement by carrying out the same process without connecting the branch end to the vacuum reservoir. To determine the xylem water potential (MPa) at each time, we cut two leaves from the branch that were bagged at least $1 \mathrm{~h}$ before each measurement. The water potential was measured with a Schölander pressure chamber (PMS Instrument Company, Albany, OR, USA), and the two leaves values were averaged. Glue was applied to the leaf cut to avoid air-entry in the branch. The branch was then removed from the apparatus and let dry on the bench for $15 \mathrm{~min}$ to hours depending on the species and the sample dryness. Measurements were ended when the branches showed strong dehydration (i. g. dry leaves). The percentage of air-discharged (PAD, \%), an analogous of PLC, was calculated as proposed by Pereira et al. (2016).

\subsubsection{Estimation of VCs parameters}

Vulnerability Curves datasets of all species and all techniques were modeled using the Fitplc package (Duursma and Choat, 2017) of $R$ software (R Core Team, 2019). The package was used to fit either percent loss of conductivity (PLC, \%) or percent air-discharge (PAD, \%) measurements with the corresponding stem water potential ( $\Psi$; MPa). The package allows to fit the data with Weibull models and provides confidence intervals (CIs) of the fitted parameters using standard profiling methods and with a non-parametric bootstrap (Duursma \& Choat, 2017). Our study was focused on three parameters: the water potential leading to $12 \%$ of the conductivity loss or $12 \%$ air-discharge $\left(\Psi_{12}\right.$, $\mathrm{MPa}$ ), the water potential leading to $50 \%$ of the conductivity loss or $50 \%$ air-discharge $\left(\Psi_{50}, \mathrm{MPa}\right)$ and the rate of embolism increase per water potential drop (Slope, \% of PLC.MPa ${ }^{-1}$ or PAD.MPa ${ }^{-1}$ ).

\subsection{Pressure-Volume curve and turgor loss point estimation}

To test the reliability of the vulnerability curves in regards to the plant water relations, additional measurements of leaf water potential at turgor loss point $\left(\pi_{\text {tlp }}\right)$ were performed. Stomatal closure (similar to turgor loss point) occurs close or before incipient embolism formation, and this could be an indicator that the resulting VCs are accurate (Creek et al., 2019; Martin-StPaul et al., 2017). Pressure-volume curves were performed for all the species (Dreyer et al., 1990; Tyree and Hammel, 1972). Pressure-volume curves were determined by progressively drying a twig bearing several leaves on a laboratory bench and measuring leaf water potential using a pressure chamber (PMS Instrument Company, Albany, OR, USA) and leaf mass at intervals of a few minutes to half an hour depending on the dehydration rate of each species. Twigs were previously rehydrated for $15 \mathrm{~h}$. Parameters of the pressurevolume curves, including the turgor loss point, were determined using an excel spreadsheet tool based on the work of Sack and Pasquet-Kok (2010). Five individual pressure-volume curves were constructed for each species during the 2019 growing season, on the same plant materials (same adults trees or seedling of the same provenance when measurements were conducted on seedlings since the material were not able anymore at the moment of measurement) used for resistance to embolism estimations. An exception was $O$. europaea for which already published values were used (Diaz-Espejo et al., 2018; HernandezSantana et al., 2016).

\subsection{Statistical analyses}

$\Psi_{50}$ and Slope values differences among methods were tested using independent samples $t$-test except for the Bench-dehydration and the Micro-CT methods, that were compared to the three other methods with a one-sample $t$-test since only a single vulnerability curve was available in this case. Additionally, methods were considered to be significantly different when their $95 \%$ confidence intervals of the vulnerability curve 


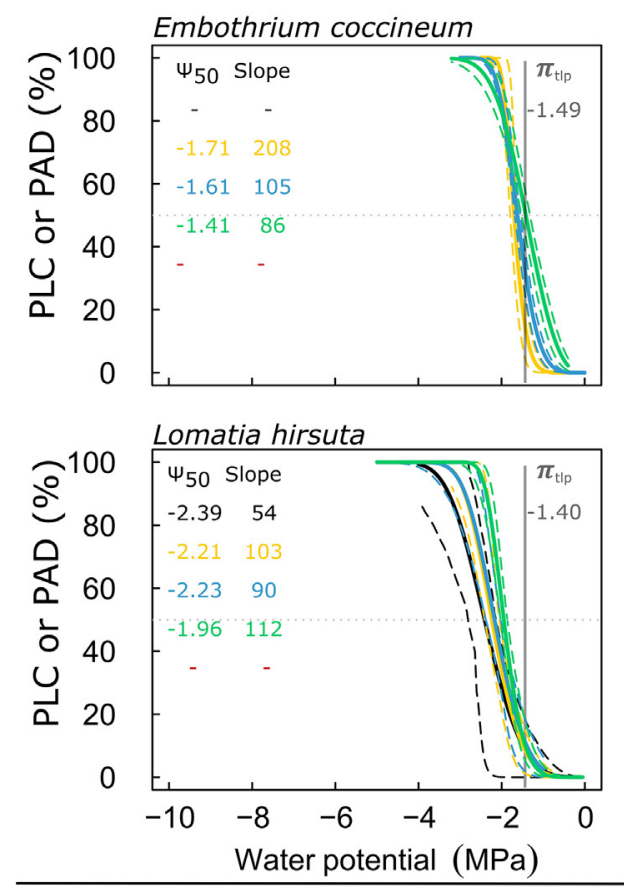

Short vessel species

Nothofagus pumilio

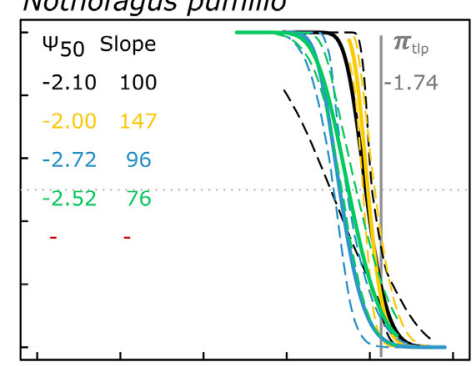

Schinus patagonicus

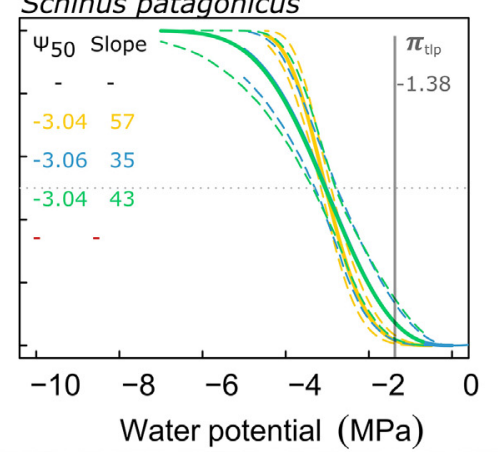

Tracheid species

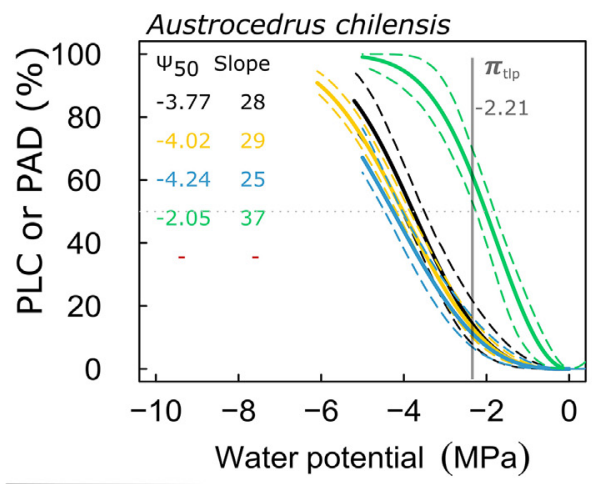

Cedrus deodara

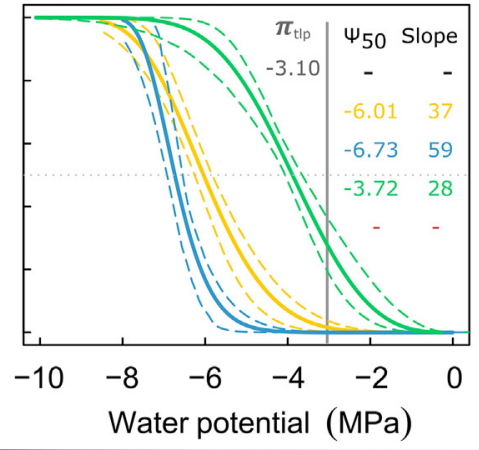

Bench dehydration

Flow-centrifuge

Air-injection

Pneumatic

Micro-CT
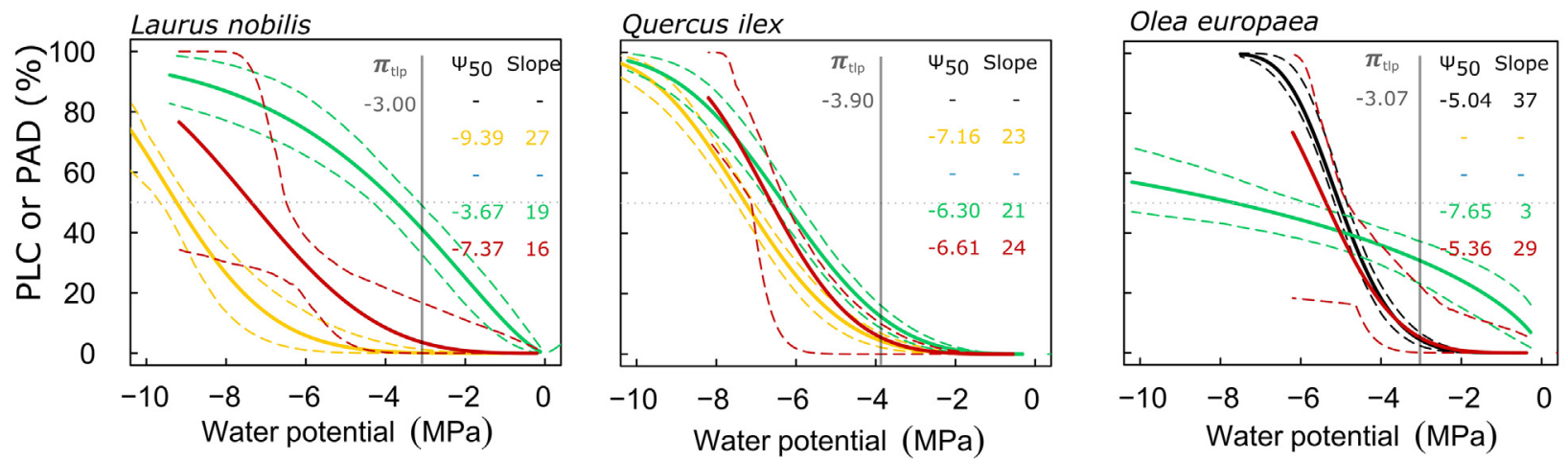

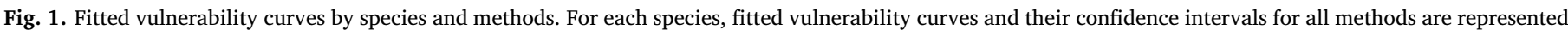

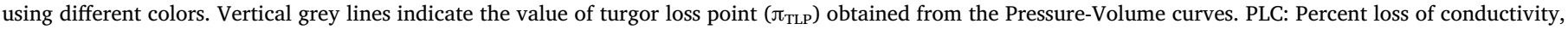

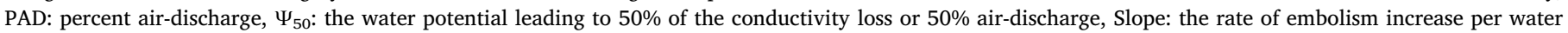
potential drop.

did not overlap for a given species. Relationships between $\Psi_{50}$ of different methods for short-vessel and tracheid species were determined by linear regression analysis. Finally, the relationship between $\pi_{\mathrm{tlp}}$ and $\Psi_{12}$ were plotted and compared to a previous meta-analysis (Martin-
StPaul et al., 2017) to assess the overall consistency of our VCs. 


\section{Results}

3.1. Comparison of patterns and parameters of vulnerability curves among tested methods

Overall, the studied species presented a wide range of embolism resistance (i.e $\Psi_{50}$ values ranged from -1.71 to $-9.39 \mathrm{MPa}$ for $E$. coccineum and $L$. nobilis, respectively with the Flow-centrifuge method) and relatively low variability in turgor loss point (from -1.4 MPa to -3.7 MPa for E. coccineum and Q. ilex, respectively) (Fig. 1).

For all the short-vessel species, vulnerability curves (VC's) evidenced similar sigmoidal (i.e. s-shaped) patterns for all the methods (Fig. 1). Additionally, we observed partial or total overlap of $95 \%$ confidence intervals of vulnerability curves between methods. Despite similarities in VC patterns, some differences between methods for $\Psi_{50}$ and Slope were observed for some species (for more details, see Supplementary Material 4, Table S2). Comparing different methods significant observed differences in $\Psi_{50}$ were in general low ( $<0.50 \mathrm{MPa}$ ) except for $N$. pumilio and M. boaria (Supplementary Material 4). In these species, $\Psi_{50}$ obtained with Bench-dehydration and Flow-centrifuge methods showed a significantly lower resistance to embolism (up to $0.89 \mathrm{MPa}$ ) compared to the $\Psi_{50}$ obtained with Airinjection and Pneumatic methods. Despite these differences, for all pairs of methods, short-vessel species $\Psi_{50}$ were highly correlated $\left(\mathrm{R}^{2}\right.$ ranged from 0.96 to 0.99 ) and aligned on the 1:1 line (Fig. 2) indicating that all methods rank properly the overall embolism resistance.
Regarding the Slope values, no clear trends were observed among methods or species albeit some differences were observed for M. boria, $N$. antarctica, L. hirsuta and E. coccineum. For the Flow-centrifuge method, the slope values of the three less resistant species departed strongly from the 1:1 line when compared to the bench-dehydration and other methods (for further details see Supplementary Material 6, Fig. S3). Regardless of the methods used, $\Psi_{50}$ and Slope values were nonlinearly related to each other (Supplementary Material 5, Fig. S2).

For tracheids-bearing species, all the methods except for the Pneumatic method, allowed to build VC that evidenced similar s-shaped patterns. The Pneumatic method tend to underestimate the resistance to cavitation for the conifer studied species (Fig. 1), significant observed differences in $\Psi_{50}$ between the Pneumatic method vs. the flow-centrifuge method ranged from 1.97 to $2.29 \mathrm{MPa}$ (Supplementary Material 4, Table S2). In both species similar significant differences were found when the Pneumatic method was compared to the Flow-centrifuge and the Air-injection methods, leading to a clear departure from the 1:1 line when the Pneumatic method was compared to other methods (Fig. 2). No significant differences were found for the Slope among methods.

For long-vessel species, consistent vulnerability s-shape curves were obtained with all methods in $Q$. ilex but not in $L$. nobilis and in $O$. europaea. In these last, the pneumatic method yielded r-shape VCs (Fig. 1) with a significant underestimation of $\Psi_{50}(3.70 \mathrm{MPa})$ in $L$. nobilis and a significant overestimation of $\Psi_{50}(2.28 \mathrm{MPa})$ in $O$. europaea when compared to the Micro-CT method, resulting in departures of the 1:1 line (Fig. 2). Additionally, a difference of $5.72 \mathrm{MPa}$ was
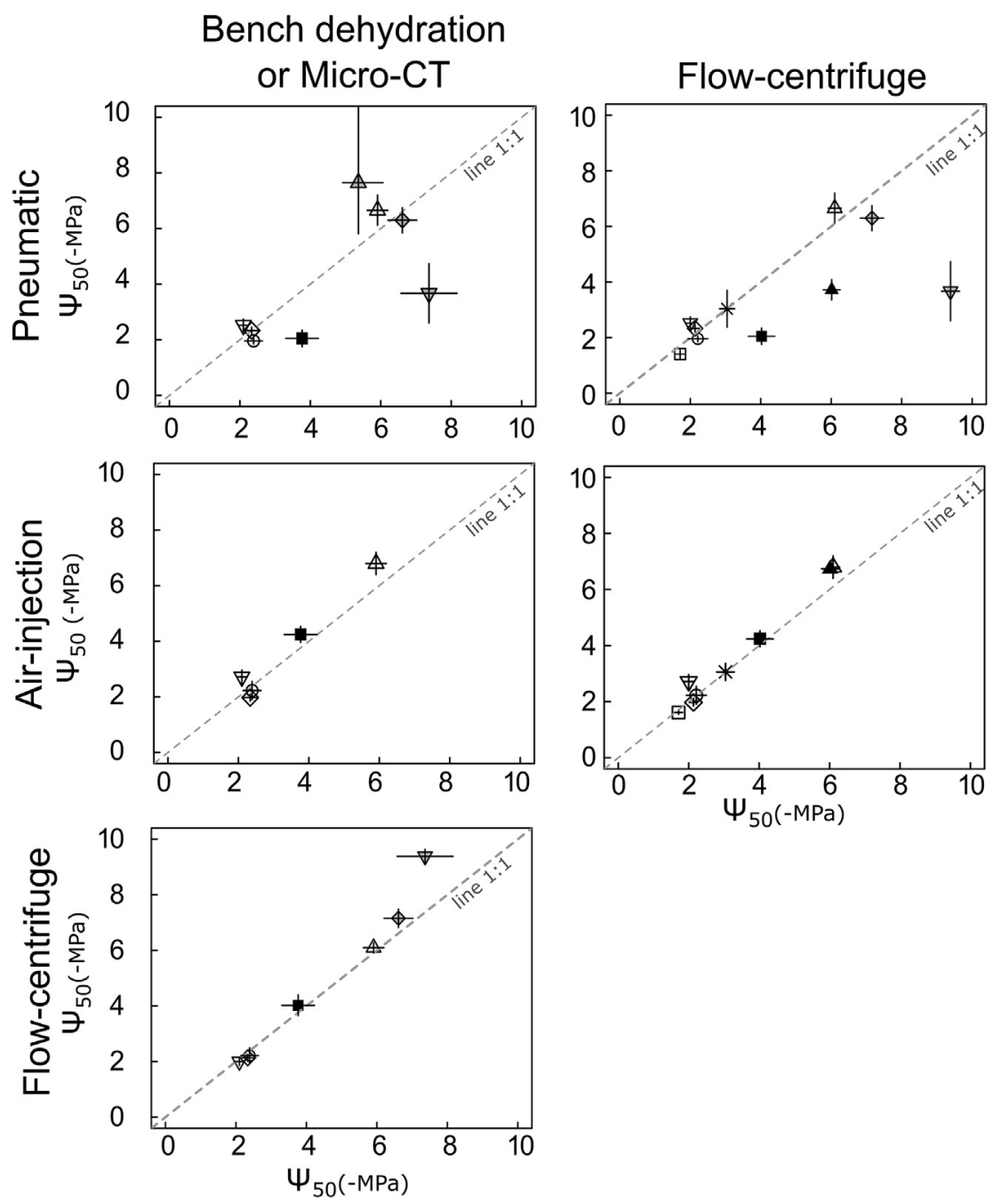

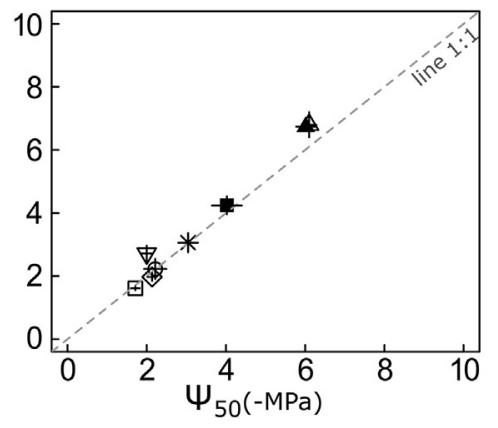

Fig. 2. Comparisons of methods for $\Psi_{50}$ measurements. Grey dashed line represents the 1:1 line. 

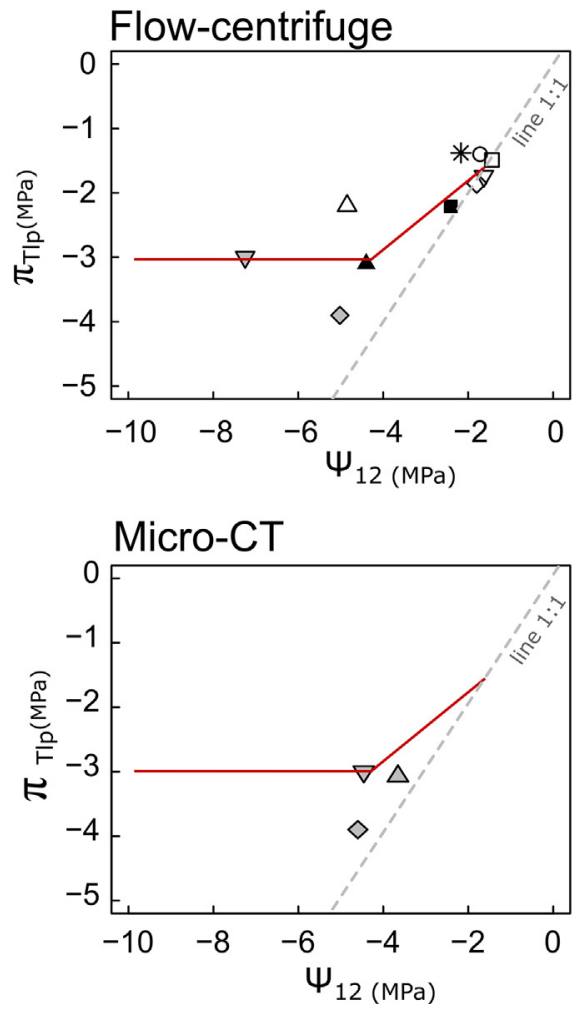

Pneumatic

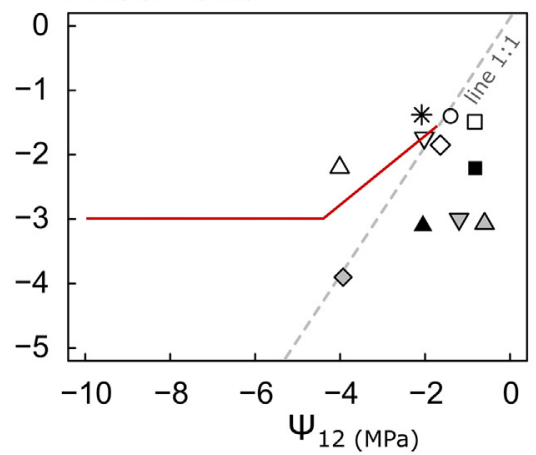

Bench-dehydration

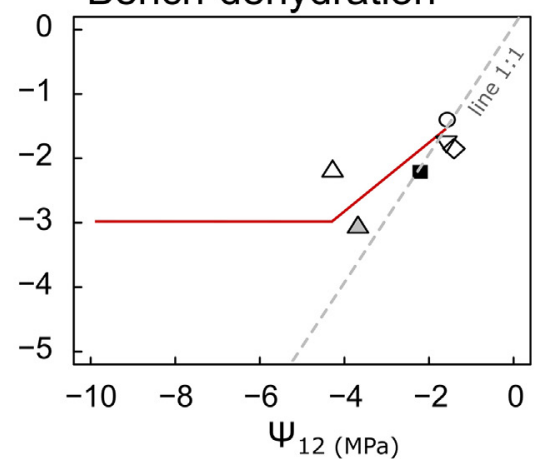

Air-injection
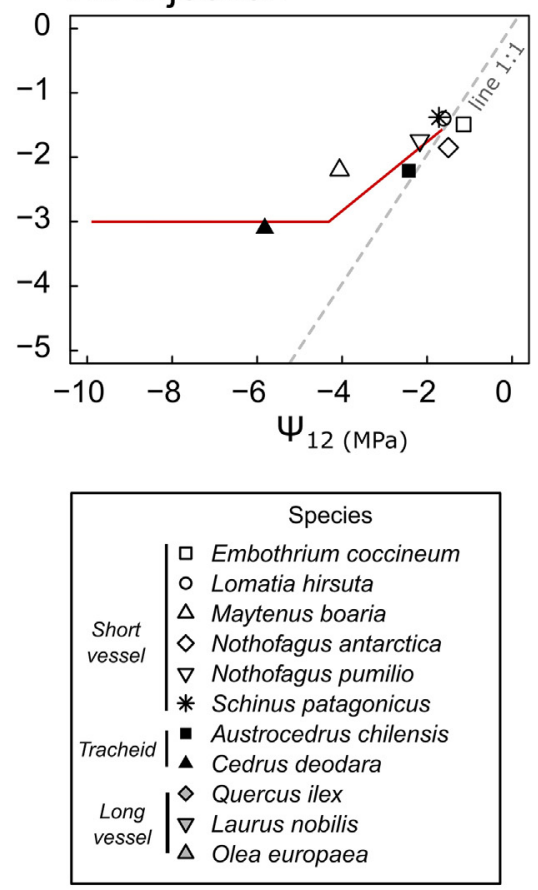

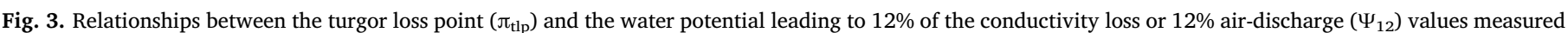

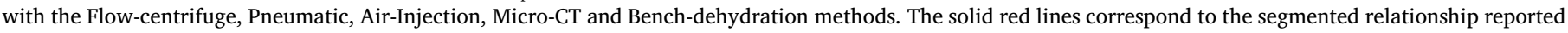

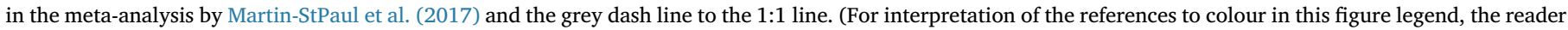
is referred to the web version of this article.)

observed when the Pneumatic method was compared with the Flowcentrifuge method in $L$. nobilis. However, for the long vessel, $Q$. ilex all methods aligned on to the 1:1 line (Fig. 2).

\subsection{Relationships between incipient embolism and turgor loss point}

Fig. 3 depicts the relationship between the $\pi_{\text {tlp }}$ and $\Psi_{12}$ (i.e. $12 \%$ PLC or PAD) obtained with the different methods. The solid segmented line (broken stick models) represents the expected relationship observed in a previous meta-analysis (Martin-StPaul et al., 2017). For all methods except for the Pneumatic one, the turgor loss point was higher (less negative) than or very close to $\Psi_{12}$. For the two gymnosperms species as well as for L. nobilis and O. europaea, two of the three studied long-vessel angiosperm species, the $\pi_{\text {tlp }}$ was much lower than the $\Psi_{12}$ values estimated from the Pneumatic method, therefore being on the right-side of the 1:1 line (Fig. 3), for more details, see Supplementary Material 7 (Table. S3).

3.3. Relationship of $\Psi_{50}$ at the individual and population scales using Airinjection and Flow-centrifuge methods

For one species (A. chilensis), we evaluated the ability of two high throughput methods (Air-injection and Flow-centrifuge methods) to estimate embolism resistance at the intraspecific level, by comparing individual values from three different populations, (additional information about populations tested in Supplementary Material 2). Fig. 4 shows a significant correlation between $\Psi_{50}$ at the individual and the population level scale obtained with both methods (at individual level, $\left.\mathrm{R}^{2}=0.73, p<0.0001\right)$. Most of the variation of $\Psi_{50}$ came from differences at the population level, which indicates that both methods gave consistent embolism resistance ranking for populations of this species.

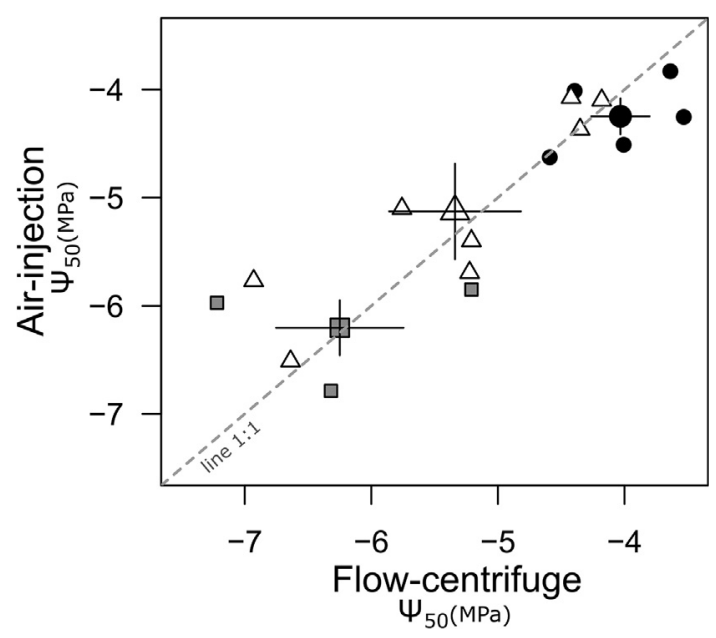

Fig. 4. Comparison of embolism resistance $\left(\Psi_{50}\right)$ obtained with the Air-injection and the Flow- centrifuge methods for same individuals of Austrocedrus chilensis collected in three different populations. Symbols and colors indicate the different populations (square $=$ La Fragua, triangle $=$ Rio Azul, dot $=$ Cerro Otto). Small symbols correspond to individual values of $\Psi_{50}$ and large symbols represent the mean population values and the corresponding standard deviation of $\Psi_{50}$. Populations are indicated by different shades of grey. The dash line represents the 1:1 line.

\section{Discussion and conclusion}

4.1. Method comparison according to species xylem anatomy and vessel length type

In the case of short vessel species, all the methods produced 
accurate results whatever the species as revealed by the good correlations among methods for $\Psi_{50}$. Additionally, for all the methods tested the turgor-loss point $\left(\pi_{\mathrm{tlp})}\right.$ was very close to or higher than the water potential causing incipient xylem embolism $\left(\Psi_{12}\right)$. This is consistent with the overall expectation that, in the sequence of the physiological response to drought, plants should lose their leaf turgor before drought induced cavitation (Brodribb and Holbrook, 2003; Creek et al., 2019; Li et al., 2018; Martin-StPaul et al., 2017; Skelton et al., 2018).

In the case of tracheid-bearing species, similar values of $\Psi_{50}$ and Slope were found for the tested methods except for the Pneumatic one. Indeed, the Pneumatic method overestimated the mean species vulnerability to embolism of the two conifers tested by up to $45 \%$ compared to other tested methods. This finding was in agreement with previous studies that explored the validity of this recently developed method in conifers (Pereira et al., 2016; Zhang et al., 2018). Tracheids obstruction by resin or the aspiration of torus-margo pit membranes (Bouche et al., 2014) could explain the discrepancy between methods (Zhang et al., 2018). When a pit membrane is subject to a certain pressure difference between neighboring tracheids, the torus could become aspirated and seal the pit aperture (Cochard et al., 2009; Jansen et al., 2012), thus preventing airflow from one tracheid to another. Pit membrane aspiration might underestimate the amount of air discharged during a pneumatic measurement, and the maximum PAD would be reached at a less negative water potential, thus resulting in a underestimation of xylem embolism resistance (Zhang et al., 2018). The Pneumatic method should therefore not be used for evaluating the resistance to embolism in gymnosperms unless these issues can be solved on further studies. Additionally, our results confirm that the Flowcentrifuge and the Air-injection methods are both consistent for gymnosperms. To further address the inter-comparability of these two methods, we tested them on three distinct populations of $A$. chilensis growing in contrasted climatic conditions. We found a consistent similar variability in $\Psi_{50}$ for the two methods (from -3.53 to -7.27 among individuals) which is within the range of the variability previously reported for this species, from $-2.12 \mathrm{MPa}$ up to $-9.95 \mathrm{MPa}$ (Bouche et al., 2014; Gyenge et al., 2005; Pittermann et al., 2012; Scholz et al., 2014). Moreover, a relatively good correlation was evidenced between the two techniques tested here. Altogether, these results indicate that the evidenced variability likely reflects meaningful biological patterns and that both methods can be used to study the intraspecific variability of this conifer.

There has been a long-standing controversy regarding the measurement of embolism resistance in long vessel species (Cochard et al., 2013). Pioneering studies showed that the Flow-centrifuge and the Airinjection technique generally lead to the so-called $r$-shaped VCs when samples with vessels cut-open are used, which causes large under-estimation of embolism resistance (Cochard et al., 2010; Choat et al., 2010; Martin-StPaul et al., 2014; Torres-Ruiz et al., 2014). Additionally, further studies showed that long vessel species are subjected to a "cutting artifact" that is responsible for an artificially high level of embolism during sample collection also causing r-shaped vulnerability curves (Torres-Ruiz et al., 2015; Wheeler et al., 2013). By using X-ray micro-tomography in synchrotron facilities, it has been possible to build vulnerability curves on intact plants to avoid open-vessel and cutting artifacts (Choat et al.,2015; Cochard et al., 2015). Such a procedure is costly and time-consuming but allows to obtain reliable vulnerability curves. In our study, X-ray micro-tomography was used to produce VCs for the studied long vessel species (Q. ilex, L. nobilis and O. europaea). These data yielded sigmoidal VC with low $\Psi_{50}(-5.36,-6.61$ and $-7.37 \mathrm{MPa}$ respectively for $O$. europaea, Q. ilex and L. nobilis) which is consistent with the Mediterranean biome of origin of these three species. For $Q$. ilex and $L$. nobilis, the micro-CT vulnerability curves were also similar to the VC obtained with the one-meter long Flow-centrifuge rotor. Such results confirm that using xylem samples longer than the maximum vessel length of the species and the correct rotor length with the Flow-centrifuge method allows avoiding the open-vessel artifact
(Charrier et al., 2016; Zhang et al., 2018; Lamarque et al., 2018). In this study, the Air-injection method was not tested for these species, but previous studies already indicated that using long samples with the Airinjection method could solve the open-vessel artifact issue (Choat et al., 2010; Ennajeh et al., 2011b; Martin-StPaul et al., 2014). The Pneumatic method has been proposed to be a good candidate to accurately measure VC on long vessel species at high throughput and low-cost (Pereira et al., 2016; 2019). Zhang et al. (2018) reported a relatively good agreement between the $\Psi_{50}$ of $1 \mathrm{~m}$-long rotor Flow-centrifuge and $\Psi_{50}$ of Pneumatic method, albeit the fact that Pneumatic method tended to produce lower slopes (and thus less negative $\Psi_{12}$ ) than the Flow-centrifuge method. Our results contradict this view as contrasted results were observed regarding the validity of the Pneumatic method on long vessel species when compared to the Micro-CT method. For $Q$. ilex, we found an overall good agreement between the Pneumatic and the Micro-CT. However, for L. nobilis and O. europaea, the Pneumatic method largely underestimated the water potential causing incipient embolism formation $\left(\Psi_{12}\right)$ and Slope. The discrepancies of the Pneumatic method compared to other tested methods in L. nobilis and $O$. europaea may be related to the abundance of tiny vessels, which may cause an important uncertainty in the amount of air discharge during dehydration captured by the pressure sensor. These results suggest that the Pneumatic method is likely not suitable for some long-vessel species. The underlying causes should be further explored to properly frame the type of xylem anatomy that can be measured with this method.

\subsection{Concluding statements: Summary of advantages and pitfalls of the different techniques}

Many methods are available to build VCs for researchers who aim to explore the xylem resistance to embolism both between and within species. Those methods vary by the way the water stress is induced and embolism is measured (Cochard et al., 2013). However, selecting the correct and most accurate method is therefore not always a simple task. Here, different methods were explored on various xylem anatomy types. Some non-invasive methods including the acoustic (Milburn and Johnson, 1966) and the optical method (Brodribb et al., 2017) were not tested in this study and should be treated in further studies, in particular, the optical method that has been intensively used over the last five years (e.g. (Emilio et al., 2019; Rodriguez-Dominguez et al., 2018; Skelton et al., 2018).

To conclude, based on our results and current knowledge, we provide a reading grid (Table 2) that summarizes the advantages and pitfalls of the different studied methods. We hope that the reader can find some basic information regarding what method is the most appropriate according to its scientific question and the xylem anatomy of its species of interest and potential artifacts. Whatever the method used, we recommend to cross-validate with another method and/or, if possible, with a non-invasive method. Moreover, in our study, we systematically compared embolism thresholds with $\pi_{\text {tlp }}$ to check the consistency of the embolism resistance parameters obtained with each method. Estimation of $\pi_{\text {tlp }}$ is generally easy, little prone to artifact and should thus be systematically measured. We encourage researchers to verify the overall biological consistency of VCs by using additional datasets related to stomatal and/or hydraulic functioning (Cochard et al., 2019; Creek et al., 2019; Martin-StPaul et al., 2014, Skelton et al., 2018).

\section{CRediT authorship contribution statement}

A.S. Sergent: Investigation, Data curation, Formal analysis, Writing - original draft, Writing - review \& editing. S.A. Varela: Investigation, Formal analysis, Writing - original draft, Writing - review \& editing. T.S. Barigah: Investigation, Writing - review \& editing. E. Badel: Investigation, Writing - review \& editing. H. Cochard: Investigation, Writing - review \& editing. G. Dalla-Salda: Writing - review \& editing. 
S. Delzon: Investigation, Writing - review \& editing. M.E. Fernández: Writing - review \& editing. J. Guillemot: Investigation, Writing - review \& editing. J. Gyenge: Writing - review \& editing. L.J. Lamarque: Investigation, Writing - review \& editing. A. Martinez-Meier: Writing review \& editing, Project administration. P. Rozenberg: Funding acquisition, Project administration. J.M. Torres-Ruiz: Investigation, Writing - review \& editing. N.K. Martin-StPaul: Investigation, Data curation, Formal analysis, Writing - original draft, Writing - review \& editing.

\section{Declaration of Competing Interest}

The authors declare that they have no known competing financial interests or personal relationships that could have appeared to influence the work reported in this paper.

\section{Acknowledgments}

This study was funded by Commission of the European Communities (H2020-MSCA-RISE-2014-645654 - TOPWOOD project) and by HELVETAS Swiss Intercooperation-Switzerland (CONDESAN -"Morpho-physiological responses to management and climate of different species of the Patagonian Andean mixed forest: Bases for its sustainable management in the framework of Climate Change" project).

\section{Appendix A. Supplementary material}

Supplementary data to this article can be found online at https:// doi.org/10.1016/j.foreco.2020.118175.

\section{References}

Alder, N.N., Pockman, W.T., Sperry, J.S., Nuismer, S., 1997. Use of centrifugal force in the study of xylem cavitation. J. Exp. Bot. 48, 665-674. https://doi.org/10.1093/jxb/48. 3.665 .

Bouche, P.S., Larter, M., Domec, J.-C., Burlett, R., Gasson, P., Jansen, S., Delzon, S., 2014 A broad survey of hydraulic and mechanical safety in the xylem of conifers. J. Exp. Bot. 65, 4419-4431. https://doi.org/10.1093/jxb/eru218.

Bréda, N., Cochard, H., Dreyer, E., Granier, A., 1993. Field comparison of transpiration, stomatal conductance and vulnerability to cavitation of Quercus petraea and Quercus robur under water stress. Ann. Sci. For. 50, 571-582. https://doi.org/10.1051/ forest:19930606.

Brodersen, C.R., McElrone, A.J., Choat, B., Matthews, M.A., Shackel, K.A., 2010. The Dynamics of Embolism Repair in Xylem. In Vivo Visualizations Using HighResolution Computed Tomography. Plant Physiol. 154, 1088-1095. https://doi.org/ 10.1104/pp.110.162396.

Brodribb, T.J., Carriqui, M., Delzon, S., Lucani, C., 2017. Optical Measurement of Stem Xylem Vulnerability. Plant Physiol. 174, 2054-2061. https://doi.org/10.1104/pp.17. 00552 .

Brodribb, T.J., Holbrook, N.M., 2003. Stomatal Closure during Leaf Dehydration, Correlation with Other Leaf Physiological Traits. Plant Physiol. 132, 2166-2173. https://doi.org/10.1104/pp.103.023879.

Charrier, G., Torres-Ruiz, J.M., Badel, E., Burlett, R., Choat, B., Cochard, H., Delmas, C.E.L., Domec, J.-C., Jansen, S., King, A., Lenoir, N., Martin-StPaul, N., Gambetta, G.A., Delzon, S., 2016. Evidence for Hydraulic Vulnerability Segmentation and Lack of Xylem Refilling under Tension. Plant Physiol. 172, 1657-1668. https://doi.org/10. 1104/pp.16.01079.

Chauvin, T., Cochard, H., Segura, V., Rozenberg, P., 2019. Native-source climate determines the Douglas-fir potential of adaptation to drought. For. Ecol. Manag. 444, 9-20. https://doi.org/10.1016/j.foreco.2019.03.054.

Choat, B., Brodersen, C.R., McElrone, A.J., 2015. Synchrotron X-ray microtomography of xylem embolism in Sequoia sempervirens saplings during cycles of drought and recovery. New Phytol. 205, 1095-1105. https://doi.org/10.1111/nph.13110.

Choat, B., Drayton, W.M., Brodersen, C., Matthews, M.A., Shackel, K.A., Wada, H., Mcelrone, A.J., 2010. Measurement of vulnerability to water stress-induced cavitation in grapevine: a comparison of four techniques applied to a long-vesseled species. Plant Cell Environ. 33, 1502-1512. https://doi.org/10.1111/j.1365-3040.2010. 02160.x.

Choat, B., Jansen, S., Brodribb, T.J., Cochard, H., Delzon, S., Bhaskar, R., Bucci, S.J., Feild, T.S., Gleason, S.M., Hacke, U.G., Jacobsen, A.L., Lens, F., Maherali, H., Martínez-Vilalta, J., Mayr, S., Mencuccini, M., Mitchell, P.J., Nardini, A., Pittermann, J., Pratt, R.B., Sperry, J.S., Westoby, M., Wright, I.J., Zanne, A.E., 2012. Global convergence in the vulnerability of forests to drought. Nature 491, 752-755. https:// doi.org/10.1038/nature11688.

Cochard, H., 2002. A technique for measuring xylem hydraulic conductance under high 
negative pressures. Plant Cell Environ. 25, 815-819. https://doi.org/10.1046/j.13653040.2002.00863.x.

Cochard, H., Badel, E., Herbette, S., Delzon, S., Choat, B., Jansen, S., 2013. Methods for measuring plant vulnerability to cavitation: a critical review. J. Exp. Bot. 64 (15), 4779-4791. https://doi.org/10.1093/jxb/ert193.

Cochard, H., Barigah, S.T., Kleinhentz, M., Eshel, A., 2008. Is xylem cavitation resistance a relevant criterion for screening drought resistance among Prunus species? J. Plant Physiol. 165, 976-982. https://doi.org/10.1016/j.jplph.2007.07.020.

Cochard, H., Bréda, N., Granier, A., 1996. Whole tree hydraulic conductance and water loss regulation in Quercus during drought: evidence for stomatal control of embolism? Ann. Sci. For. 53, 197-206. https://doi.org/10.1051/forest:19960203.

Cochard, H., Cruiziat, P., Tyree, M.T., 1992. Use of Positive Pressures to Establish Vulnerability Curves: Further Support for the Air-Seeding Hypothesis and Implications for Pressure-Volume Analysis. Plant Physiol. 100, 205-209. https://doi. org/10.1104/pp.100.1.205.

Cochard, H., Damour, G., Bodet, C., Tharwat, I., Poirier, M., Améglio, T., 2005. Evaluation of a new centrifuge technique for rapid generation of xylem vulnerability curves. Physiol. Plant. 124, 410-418. https://doi.org/10.1111/j.1399-3054.2005. 00526.x.

Cochard, H., Delzon, S., Badel, E., 2015. X-ray microtomography (micro-CT): a reference technology for high-resolution quantification of xylem embolism in trees. Plant Cell Environ. 38, 201-206. https://doi.org/10.1111/pce.12391.

Cochard, H., Herbette, S., Barigah, T., Badel, E., Ennajeh, M., Vilagrosa, A., 2010. Does sample length influence the shape of xylem embolism vulnerability curves? A test with the Cavitron spinning technique. Plant Cell Environ. 33, 1543-1552. https:// doi.org/10.1111/j.1365-3040.2010.02163.x.

Cochard, H., Hölttä, T., Herbette, S., Delzon, S., Mencuccini, M., 2009. New Insights into the Mechanisms of Water-Stress-Induced Cavitation in Conifers. Plant Physiol. 151, 949-954. https://doi.org/10.1104/pp.109.138305.

Cochard, H., Petit, G., Torres-Ruiz, J.M., Delzon, S., 2019. XIM4 meeting report, Sept. 25-27 2019, Padua (Italy). J. Plant Hydraul. 6, e002. https://doi.org/10.20870/jph. 2019.e002.

Creek, D., Lamarque, L.J., Torres-Ruiz, J.M., Parise, C., Burlett, R., Tissue, D.T., Delzon, S., 2019. Xylem embolism in leaves does not occur with open stomata: evidence from direct observations using the optical visualisation technique. J. Exp. Bot. https://doi. org/10.1093/jxb/erz474.

Delzon, S., Douthe, C., Sala, A., Cochard, H., 2010. Mechanism of water-stress induced cavitation in conifers: bordered pit structure and function support the hypothesis of seal capillary-seeding. Plant Cell Environ. 33, 2101-2111. https://doi.org/10.1111/j. 1365-3040.2010.02208.x.

Diaz-Espejo, A., Fernández, J.E., Torres-Ruiz, J.M., Rodriguez-Dominguez, C.M., PerezMartin, A., Hernandez-Santana, V., 2018. Chapter 18 - The Olive Tree Under Water Stress: Fitting the Pieces of Response Mechanisms in the Crop Performance Puzzle. In: García Tejero, I.F., Durán Zuazo, V.H. (Eds.), Water Scarcity and Sustainable Agriculture in Semiarid Environment. Academic Press, pp. 439-479. https://doi.org/ 10.1016/B978-0-12-813164-0.00018-1.

Dierick, M., Masschaele, B., Hoorebeke, L.V., 2004. Octopus, a fast and user-friendly tomographic reconstruction package developed in LabView ${ }^{\oplus}$. Meas. Sci. Technol. 15, 1366-1370. https://doi.org/10.1088/0957-0233/15/7/020.

Dreyer, E., Bousquet, F., Ducrey, M., 1990. Use of pressure volume curves in water relation analysis on woody shoots: influence of rehydration and comparison of four European oak species. Ann. Sci. For. 47, 285-297. https://doi.org/10.1051/ forest:19900401.

Duursma, R., Choat, B., 2017. fitplc - an R package to fit hydraulic vulnerability curves. J. Plant Hydraul. 4, e002. https://doi.org/10.20870/jph.2017.e002.

Emilio, T., Lamarque, L.J., Torres-Ruiz, J.M., King, A., Charrier, G., Burlett, R., Conejero, M., Rudall, P.J., Baker, W.J., Delzon, S., 2019. Embolism resistance in petioles and leaflets of palms. Ann. Bot. https://doi.org/10.1093/aob/mcz104.

Ennajeh, M., Nouiri, M., Khemira, H., Cochard, H., 2011a. Improvement to the air-injection technique to estimate xylem vulnerability to cavitation. Trees 25, 705-710. https://doi.org/10.1007/s00468-011-0548-8.

Ennajeh, M., Simões, F., Khemira, H., Cochard, H., 2011b. How reliable is the doubleended pressure sleeve technique for assessing xylem vulnerability to cavitation in woody angiosperms? Physiol. Plant. 142, 205-210. https://doi.org/10.1111/j.13993054.2011.01470.x.

Ewers, F.W., Fisher, J.B., 1989. Techniques for Measuring Vessel Lengths and Diameters in Stems of Woody Plants. Am. J. Bot. 76, 645-656. https://doi.org/10.2307/ 2444412 .

Gyenge, J.E., Fernández, M.E., Dalla Salda, G., Schlichter, T., 2005. Leaf and whole-plant water relations of the Patagonian conifer Austrocedrus chilensis (D. Don) Pic. Ser. et Bizzarri: implications on its drought resistance capacity. Ann. For. Sci. 62, 297-302. https://doi.org/10.1051/forest:2005024.

Hernandez-Santana, V., Rodriguez-Dominguez, C.M., Fernández, J.E., Diaz-Espejo, A., 2016. Role of leaf hydraulic conductance in the regulation of stomatal conductance in almond and olive in response to water stress. Tree Physiol. 36, 725-735. https://doi. org/10.1093/treephys/tpv146.

Jansen, S., Lamy, J.-B., Burlett, R., Cochard, H., Gasson, P., Delzon, S., 2012. Plasmodesmatal pores in the torus of bordered pit membranes affect cavitation resistance of conifer xylem. Plant Cell Environ. 35, 1109-1120. https://doi.org/10 1111/j.1365-3040.2011.02476.x.

Jones, H.G., Sutherland, R.A., 1991. Stomatal control of xylem embolism. Plant Cell Environ. 14, 607-612. https://doi.org/10.1111/j.1365-3040.1991.tb01532.x.

King, A., Guignot, N., Zerbino, P., Boulard, E., Desjardins, K., Bordessoule, M., Leclerq, N., Le, S., Renaud, G., Cerato, M., Bornert, M., Lenoir, N., Delzon, S., Perrillat, J.-P., Legodec, Y., Itié, J.-P., 2016. Tomography and imaging at the PSICHE beam line of the SOLEIL synchrotron. Rev. Sci. Instrum. 87, 093704. https://doi.org/10.1063/1.
4961365.

Lamarque, L.J., Corso, D., Torres-Ruiz, J.M., Badel, E., Brodribb, T.J., Burlett, R. Charrier, G., Choat, B., Cochard, H., Gambetta, G.A., Jansen, S., King, A., Lenoir, N., Martin-StPaul, N., Steppe, K., Van den Bulcke, J., Zhang, Y., Delzon, S., 2018. An inconvenient truth about xylem resistance to embolism in the model species for refilling Laurus nobilis L. Ann. For. Sci. 75, 88. https://doi.org/10.1007/s13595-0180768-9.

Lamy, J.-B., Delzon, S., Bouche, P.S., Alia, R., Vendramin, G.G., Cochard, H., Plomion, C., 2013. Limited genetic variability and phenotypic plasticity detected for cavitation resistance in a Mediterranean pine. New Phytol. 201, 874-886. https://doi.org/10. 1111/nph.12556.

Larter, M., Pfautsch, S., Domec, J.-C., Trueba, S., Nagalingum, N., Delzon, S., 2017. Aridity drove the evolution of extreme embolism resistance and the radiation of conifer genus Callitris. New Phytol. 215, 97-112. https://doi.org/10.1111/nph. 14545.

Lens, F., Picon-Cochard, C., Delmas, C.E.L., Signarbieux, C., Buttler, A., Cochard, H., Jansen, S., Chauvin, T., Doria, L.C., Del Arco, M., Delzon, S., 2016. Herbaceous Angiosperms Are Not More Vulnerable to Drought-Induced Embolism Than Angiosperm Trees. Plant Physiol. 172, 661-667. https://doi.org/10.1104/pp.16. 00829 .

Li, X., Blackman, C.J., Choat, B., Duursma, R.A., Rymer, P.D., Medlyn, B.E., Tissue, D.T., 2018. Tree hydraulic traits are coordinated and strongly linked to climate-of-origin across a rainfall gradient. Plant Cell Environ. 41, 646-660. https://doi.org/10.1111/ pce. 13129.

López, R., Cano, F.J., Choat, B., Cochard, H., Gil, L., 2016. Plasticity in Vulnerability to Cavitation of Pinus canariensis Occurs Only at the Driest End of an Aridity Gradient. Funct. Plant Ecol. 769. https://doi.org/10.3389/fpls.2016.00769.

López, R., Nolf, M., Duursma, R.A., Badel, E., Flavel, R.J., Cochard, H., Choat, B., 2019. Mitigating the open vessel artefact in centrifuge-based measurement of embolism resistance. Tree Physiol. 39, 143-155. https://doi.org/10.1093/treephys/tpy083.

Maherali, H., Pockman, W.T., Jackson, R.B., 2004. Adaptive Variation in the Vulnerability of Woody Plants to Xylem Cavitation. Ecology 85, 2184-2199. https:// doi.org/10.1890/02-0538.

Martin-StPaul, N., Delzon, S., Cochard, H., 2017. Plant resistance to drought depends on timely stomatal closure. Ecol. Lett. 20, 1437-1447. https://doi.org/10.1111/ele. 12851.

Martin-StPaul, N.K., Longepierre, D., Huc, R., Delzon, S., Burlett, R., Joffre, R., Rambal, S., Cochard, H., 2014. How reliable are methods to assess xylem vulnerability to cavitation? The issue of "open vessel" artifact in oaks. Tree Physiol. 34, 894-905. https://doi.org/10.1093/treephys/tpu059.

Milburn, J.A., Johnson, R.P.C., 1966. The conduction of sap. Planta 69, 43-52. https:// doi.org/10.1007/BF00380209.

Mirone, A., Brun, E., Gouillart, E., Tafforeau, P., Kieffer, J., 2014. The PyHST2 hybrid distributed code for high speed tomographic reconstruction with iterative reconstruction and a priori knowledge capabilities. Nucl. Instrum. Methods Phys. Res. Sect. B Beam Interact. Mater. At., 1st International Conference on Tomography of Materials and Structures 324, 41-48. https://doi.org/10.1016/j.nimb.2013.09.030.

Paganin, D., Mayo, S.C., Gureyev, T.E., Miller, P.R., Wilkins, S.W., 2002. Simultaneous phase and amplitude extraction from a single defocused image of a homogeneous object. J. Microsc. 206, 33-40. https://doi.org/10.1046/j.1365-2818.2002.01010.x.

Pastorino, M.J., Aparicio, A.G., Azpilicueta, M.M., Bariloche, E.E.A., 2015. Regiones de Procedencia del Ciprés de la Cordillera, Ediciones INTA. ed. Bariloche.

Pereira, L., Bittencourt, P.R.L., Oliveira, R.S., Junior, M.B.M., Barros, F.V., Ribeiro, R.V., Mazzafera, P., 2016. Plant pneumatics: stem air flow is related to embolism - new perspectives on methods in plant hydraulics. New Phytol. 211, 357-370. https://doi. org/10.1111/nph.13905.

Pereira, L., Bittencourt, P.R.L., Pacheco, V.S., Miranda, M.T., Zhang, Y., Oliveira, R.S., Groenendijk, P., Machado, E.C., Tyree, M.T., Jansen, S., Rowland, L., Ribeiro, R.V., 2019. The Pneumatron: An automated pneumatic apparatus for estimating xylem vulnerability to embolism at high temporal resolution. Plant Cell Environ. 43 (1), 131-142. https://doi.org/10.1111/pce.13647.

Pittermann, J., Stuart, S.A., Dawson, T.E., Moreau, A., 2012. Cenozoic climate change shaped the evolutionary ecophysiology of the Cupressaceae conifers. Proc. Natl. Acad. Sci. 109, 9647-9652. https://doi.org/10.1073/pnas.1114378109.

Pockman, W.T., Sperry, J.S., 2000. Vulnerability to xylem cavitation and the distribution of Sonoran Desert vegetation. Am. J. Bot. 87, 1287-1299.

Pratt, R.B., Jacobsen, A.L., 2018. Identifying which conduits are moving water in woody plants: a new HRCT-based method. Tree Physiol. 38, 1200-1212. https://doi.org/10 1093/treephys/tpy034.

Rodriguez-Dominguez, C.M., Murphy, M.R.C., Lucani, C., Brodribb, T.J., 2018. Mapping xylem failure in disparate organs of whole plants reveals extreme resistance in olive roots. New Phytol. 218, 1025-1035. https://doi.org/10.1111/nph.15079.

$\mathrm{R}$ Core Team, 2019. R: A language and environment for statistical computing. R Foundation for Statistical Computing, Vienna, Austria. URL: https://www.R-project. org/.

Sack, L., Pasquet-Kok, J., and PrometheusWiki contributors. 2010. Leaf pressure-volume curve parameters. PrometheusWiki. Available at: /tiki-pagehistory.php?page = Leaf pressure-volume curve parameters\&preview $=16$. Accessed November 28, 2019.

Salleo, S., Hinckley, T.M., Kikuta, S.B., Gullo, M. a. L., Weilgony, P., Yoon, T.-M., Richter, H., 1992. A method for inducing xylem emboli in situ: experiments with a fieldgrown tree. Plant Cell Environ. 15, 491-497. https://doi.org/10.1111/j.1365-3040. 1992.tb01001.x.

Salleo, S., Nardini, A., Pitt, F., Gullo, M.A.L., 2000. Xylem cavitation and hydraulic control of stomatal conductance in Laurel (Laurus nobilis L.). Plant Cell Environ. 23, 71-79. https://doi.org/10.1046/j.1365-3040.2000.00516.x.

Scholz, F.G., Bucci, S.J., Goldstein, G., 2014. Strong hydraulic segmentation and leaf 
senescence due to dehydration may trigger die-back in Nothofagus dombeyi under severe droughts: a comparison with the co-occurring Austrocedrus chilensis. Trees 28, 1475-1487. https://doi.org/10.1007/s00468-014-1050-x.

Skelton, R.P., Dawson, T.E., Thompson, S.E., Shen, Y., Weitz, A.P., Ackerly, D., 2018. Low Vulnerability to Xylem Embolism in Leaves and Stems of North American Oaks. Plant Physiol. 177, 1066-1077. https://doi.org/10.1104/pp.18.00103.

Sperry, J.S., 1986. Relationship of Xylem Embolism to Xylem Pressure Potential, Stomatal Closure, and Shoot Morphology in the Palm Rhapis excelsa. Plant Physiol. 80, 110-116. https://doi.org/10.1104/pp.80.1.110.

Sperry, J.S., Hacke, U.G., Oren, R., Comstock, J.P., 2002. Water deficits and hydraulic limits to leaf water supply. Plant Cell Environ. 25, 251-263. https://doi.org/10. 1046/j.0016-8025.2001.00799.x.

Sperry, J.S., Pockman, W.T., 1993. Limitation of transpiration by hydraulic conductance and xylem cavitation in Betula occidentalis. Plant Cell Environ. 16, 279-287. https:// doi.org/10.1111/j.1365-3040.1993.tb00870.x.

Sperry, J.S., Saliendra, N.Z., 1994. Intra- and inter-plant variation in xylem cavitation in Betula occidentalis. Plant Cell Environ. 17, 1233-1241. https://doi.org/10.1111/j. 1365-3040.1994.tb02021.x.

Torres-Ruiz, J.M., Cochard, H., Choat, B., Jansen, S., López, R., Tomášková, I., PadillaDíaz, C.M., Badel, E., Burlett, R., King, A., Lenoir, N., Martin-StPaul, N.K., Delzon, S. 2017. Xylem resistance to embolism: presenting a simple diagnostic test for the open vessel artefact. New Phytol. 215, 489-499. https://doi.org/10.1111/nph.14589.

Torres-Ruiz, J.M., Cochard, H., Mayr, S., Beikircher, B., Diaz-Espejo, A., RodriguezDominguez, C.M., Badel, E., Fernández, J.E., 2014. Vulnerability to cavitation in Olea europaea current-year shoots: further evidence of an open-vessel artifact associated with centrifuge and air-injection techniques. Physiol. Plant. 152, 465-474. https:// doi.org/10.1111/ppl.12185.

Torres-Ruiz, J.M., Jansen, S., Choat, B., McElrone, A.J., Cochard, H., Brodribb, T.J., Badel, E., Burlett, R., Bouche, P.S., Brodersen, C.R., Li, S., Morris, H., Delzon, S., 2015. Direct X-Ray Microtomography Observation Confirms the Induction of Embolism upon Xylem Cutting under Tension. Plant Physiol. 167, 40-43. https://doi. org/10.1104/pp.114.249706.
Torres-Ruiz, J.M., Kremer, A., Carins Murphy, M.R., Brodribb, T., Lamarque, L.J., Truffaut, L., Bonne, F., Ducousso, A., Delzon, S., 2019. Genetic differentiation in functional traits among European sessile oak populations. Tree Physiol. https://doi. org/10.1093/treephys/tpz090.

Tyree, M.T., Dixon, M.A., 1986. Water stress induced cavitation and embolism in some woody plants. Physiol. Plant. 66, 397-405. https://doi.org/10.1111/j.1399-3054. 1986.tb05941.x.

Tyree, M.T., Hammel, H.T., 1972. The Measurement of the Turgor Pressure and the Water Relations of Plants by the Pressure-bomb Technique. J. Exp. Bot. 23, 267-282. https://doi.org/10.1093/jxb/23.1.267.

Tyree, M.T., Sperry, J.S., 1989. Vulnerability of Xylem to Cavitation and Embolism. Annu. Rev. Plant Physiol. Plant Mol. Biol. 40, 19-36. https://doi.org/10.1146/annurev. pp. 40.060189.000315.

Wheeler, J.K., Huggett, B.A., Tofte, A.N., Rockwell, F.E., Holbrook, N.M., 2013. Cutting xylem under tension or supersaturated with gas can generate PLC and the appearance of rapid recovery from embolism. Plant Cell Environ. 36, 1938-1949. https://doi. org/10.1111/pce.12139.

Wortemann, R., Herbette, S., Barigah, T.S., Fumanal, B., Alia, R., Ducousso, A., Gomory, D., Roeckel-Drevet, P., Cochard, H., 2011. Genotypic variability and phenotypic plasticity of cavitation resistance in Fagus sylvatica L. across Europe. Tree Physiol 31, 1175-1182. https://doi.org/10.1093/treephys/tpr101.

Zhang, Y., Lamarque, L.J., Torres-Ruiz, J.M., Schuldt, B., Karimi, Z., Li, S., Qin, D.-W., Bittencourt, P., Burlett, R., Cao, K.-F., Delzon, S., Oliveira, R., Pereira, L., Jansen, S., 2018. Testing the plant pneumatic method to estimate xylem embolism resistance in stems of temperate trees. Tree Physiol. 38, 1016-1025. https://doi.org/10.1093/ treephys/tpy015.

Zimmermann, M.H., 1983. Xylem Structure and the Ascent of Sap, Springer Series in Wood Science. Springer-Verlag, Berlin, Heidelberg.

Zimmermann, M.H., Jeje, A.A., 1981. Vessel-length distribution in stems of some American woody plants. Can. J. Bot. 59, 1882-1892. https://doi.org/10.1139/b81248. 